\title{
Vertebral and peripheral bone mineral content and fracture incidence in postmenopausal patients with rheumatoid arthritis: effect of low dose corticosteroids
}

\author{
A VERSTRAETEN AND J DEQUEKER
}

From the Division of Rheumatology, Department of Internal Medicine, Katholieke Universiteit Leuven, Universitaire Ziekenhuizen Leuven, B-3041 Pellenberg, Belgium

SUMmaRY Peripheral and axial bone mass and fracture incidence were studied in a group of 104 postmenopausal patients with rheumatoid arthritis (RA). Patients were divided into noncortiscosteroid and low dose corticosteroid treated groups after elimination of patients with concomitant disease or therapy which might affect bone mass. Results were compared with those obtained in controls matched for age and sex. Bone mass at the distal radius was significantly reduced compared with that of controls in both patient groups. Axial bone mass, however, was normal in both treatment groups, non-corticosteroid treated patients having even a significantly higher bone mass than controls $(\mathrm{p}<0.05)$ and corticosteroid treated patients $(\mathrm{p}<0.05)$. Fracturg incidence (vertebral and femoral neck) was significantly $(\mathrm{p}<0 \cdot 01)$ higher in corticosteroid treateg patients than in the non-corticosteroid treated group. The mean lumbar bone mineral conter and the body weight of the fracture group were significantly lower than in the controls. There were no significant differences in biochemical markers of bone turnover between the RA groups.

Key words: bone mass, single-dual photon absorptiometry.

In rheumatoid arthritis (RA) a generalised increase in bone turnover is well recognised, ${ }^{1-3}$ as is localised bone loss near affected joints. ${ }^{4-8}$

There remains, however, doubt as to whether bone loss is a generalised systemic effect of the disease process, involving also the trabecular bone of the spine, or whether it is the result of disease, localised to the involved joints.

The majority of the previous studies in RA have measured mainly cortical bone, using radiological, ${ }^{4679-12}$ single photon absorptiometry, ${ }^{18}$ or neutron activation techniques. ${ }^{13} \mathrm{~A}$ direct measurement in vivo of bone mineral content of the lumbar spine in RA has not been done. At present two techniques to evaluate this region are available, namely dual photon absorptiometry and computed tomography. Since the cause of bone loss in RA may

Accepted for publication 21 April 1986

Correspondence to Professor Dr J Dequeker, Division of Rheumatology, Department of Internal Medicine, UZ Pellenberg, B-3041 Pellenberg, Belgium. be multifactorial, with the duration and severity of the disease process, the administration of corticosteroids systemically, age, sex, and menopausal state all having an influence, it is necessary to control as many of these factors as possible in order to obtain unbiased results.

In some studies a more severe degree of bone loss was found in RA patients treated with corticosteroids, ${ }^{8} 1314$ but other studies did not confirm this. ${ }^{79} 11121516$ Numerous studies confirm the deleterious effects of corticosteroids on bone, especially trabecular bone, and the musculoskeletal system in other diseases. ${ }^{17-19}$

We have, therefore, prospectively studied bone mass, both peripheral and axial, and fracture incidence in a group of postmenopausal patients with RA. We have divided them into a noncorticosteroid treated group and a corticosteroid treated group after elimination of all possible interfering factors, and we have compared the results obtained in these groups with those from 
control group matched for sex, age, and menopausal status.

\section{Patients and methods}

Bone mineral content (BMC) was measured in the radius and the spine in 104 postmenopausal women with classical or definite RA (American Rheumatism Association criteria ${ }^{20}$ ) and in 43 postmenopausal controls. The patients with rheumatoid arthritis were consecutive admissions to our rheumatology unit for adjustment of therapy.

At the time of the bone mineral content measurement all patients received a check of their metabolic bone state, including biochemical (serum and urinary) parameters of calcium metabolism as previously described, ${ }^{21}$ and one $x$ ray of both hands and the spine.

Bone mineral content (BMC) at the forearm (distal radius $1 / 3$ left side) was measured by means of the Norland Cameron ${ }^{125}$ I single photon absorptiometry method, ${ }^{17}$ while lumbar BMC (L2-L3-L4) was measured by means of the Novo Lab $22{ }^{153} \mathrm{Gd}$ dual photon absorptiometry method. ${ }^{18}$

The patients with RA were divided into two groups according to whether or not they were being treated with corticosteroids systemically at the time of the evaluation or had been during the past disease course for at least six months.

Almost all patients were receiving non-steroidal anti-inflammatory drugs and all of them had been treated with one or more or were still under treatment with disease modifying antirheumatic drugs.

Forty patients were at the time of bone mineral content estimation, or had been in the past, treated with drugs such as sodium fluoride, vitamin $\mathrm{D}$, or oestrogens $(n=23)$ or had concomitant diseases such as early bilateral ovariectomy, renal insufficiency, or malignancy $(n=17)$, which might influence BMC and biochemical parameters of skeletal metabolism. The values obtained from these patients were not taken into account for further evaluation.

The fracture incidence was evaluated in the total postmenopausal RA population $(n=104)$ studied. A vertebral fracture was defined as a clear change $(>20 \%)$ in the shape of the anterior, medial, or posterior part of the vertebrae on a lateral $x$ ray of the dorsal and lumbar spine. Occurrence of other cortical bone fractures was also registered.

The control group consisted of 43 postmenopausal women who voluntarily participated in a population study of bone mineral content performed in our service. None of them had any concomitant disease or treatment which might affect bone metabolism.

\section{Results}

Characteristics of patients and controls are summarised in Table 1 . In the corticosteroid treated group there were no differences between patients treated with corticosteroids in the past and those under treatment at the time of the measurement, so they could be regarded as one entity. Sixty four per cent of the patients in the corticosteroid treated group were still on steroids at the time of the investigation. The mean dose of prednisone equivalent was 8.9 (SD 6.0) $\mathrm{mg} / \mathrm{day}$, and the mean duration of corticosteroid treatment was 4.7 (SD 4.1) years. The corticosteroid treated patients had a significantly longer disease course than the non-corticosteroid

Table 1 Characteristics of patients and controlst

\begin{tabular}{|c|c|c|c|}
\hline & $\underset{(n=36)}{\text { Group } I: R A \text { patients }}$ & $\begin{array}{l}\text { Group II: RA patients } \\
+ \text { corticosteroids }(n=28)\end{array}$ & $\begin{array}{l}\text { Controls } \\
(n=43)\end{array}$ \\
\hline $\begin{array}{l}\text { Age (years) } \\
\text { Years since menopause } \\
\text { Height (cm) } \\
\text { Weight (kg) } \\
\text { Duration of disease (years) } \\
\text { Rheumatoid factor positivity (\%) } \\
\text { Anatomic class (\%) } 1 \\
2 \\
3 \\
4 \\
\text { Functional class (\%) } 1 \\
2 \\
3 \\
4\end{array}$ & $\begin{array}{cl}59 \cdot 2 & (7 \cdot 6) \ddagger \\
10 \cdot 8 & (9 \cdot 2) \\
159 \cdot 0 & (5 \cdot 2) \\
67 \cdot 1 & (11 \cdot 0) \\
6 \cdot 2 & (6 \cdot 5) \\
68 & \\
5 \cdot 8 \\
61 \cdot 8 \\
17 \cdot 6 \\
14 \cdot 8 \\
0 \\
61 \cdot 1 \\
38 \cdot 9 \\
0\end{array}$ & $\begin{array}{l}59 \cdot 2(4 \cdot 8) \\
10.7(7 \cdot 3) \\
157 \cdot 3(4 \cdot 5) \\
61 \cdot 8(10 \cdot 2)^{*} \\
17.7(10 \cdot 3)^{* *} \\
82 \\
14 \cdot 3 \\
19 \cdot 0 \\
28 \cdot 6 \\
38 \cdot 1 \\
0 \\
40.7 \\
55.6 \\
3.7\end{array}$ & $\begin{array}{r}58.6(8.1) \\
9.6(8.6) \\
159.1(5.6) \\
67.7(9.6)\end{array}$ \\
\hline
\end{tabular}

${ }^{*} \mathrm{p}<0.05$ compared with controls (Student's $t$ test); ${ }^{* *} \mathrm{p}<0.001$ compared with group I (Student's $t$ test).

$\dagger$ Patients with concomitant disease or calcitropic therapy are not included.

$\ddagger$ Values are mean (SD). 
treated patients, and their body weight was significantly lower than that of the controls.

Table 2 provides an overview of the serum and urinary parameters of bone metabolism in both groups. As can be seen from this table, there were no significant differences between the two groups in biochemical parameters of bone turnover.

The results of the bone mineral content measurements at the radius, distal $1 / 3$, both trabecular and cortical site, and at the lumbar spine, are given in Table 3.

In both RA groups peripheral BMC values were significantly reduced compared with those in the control group. There were no significant differences between the RA groups.

Vertebral column BMC values for patients who had never been treated with corticosteroids were significantly higher than those in the control group and in the corticosteroid treated group. The last group, however, did not significantly differ from the control group.

When in the RA groups a case control study was made of patients with comparable disease duration there was no longer a difference between noncorticosteroid treated $(n=12$, mean age 64.2 (SD 5.9 ) years and mean disease duration 9.9 (SD 4.6)

Table 2 Comparison of serum and urinary parameters of bone metabolism between patients with RA treated or not treated with corticosteroids

$\begin{array}{ll}\text { Group I: RA patients } & \begin{array}{l}\text { Group II: } R A \text { patients }+ \\ \text { corticosteroids } \\ (n=36)\end{array}\end{array}$

\begin{tabular}{|c|c|c|c|}
\hline \multicolumn{4}{|l|}{ Serum } \\
\hline Total calcium $(\mathrm{mg} \%)^{*}$ & $9.0(0.4)$ & $9.0(0.4)$ & NS \\
\hline Albumin $(g \%)^{*}$ & $3.58(0.48)$ & $3.48(0 \cdot 36)$ & NS \\
\hline Ca corr. alb. $\dagger(\mathrm{mg} \%)^{*}$ & $9.4(0.5)$ & $9.5(0.5)$ & NS \\
\hline Phosphorus (mg\%) ${ }^{*}$ & $3.79(0.41)$ & $3.77(0.41)$ & NS \\
\hline Alk. phosphatase activity (IU/l) & $102 \cdot 5(21 \cdot 7)$ & $97.0(26 \cdot 5)$ & NS \\
\hline Creatinine $(\mathrm{mg} \%)^{*}$ & $0.75(0.15)$ & $0.76(0.21)$ & NS \\
\hline $\mathrm{iPTH} \dagger(\mu \mathrm{U} / \mathbf{n})$ & $56.0(31.8)$ & $69.8(34.0)$ & NS \\
\hline $25-\mathrm{OHD}_{3}(\mu \mathrm{g} / \mathrm{ml})^{*}$ & $15 \cdot 2(8 \cdot 5)$ & $18 \cdot 2(13 \cdot 6)$ & NS \\
\hline \multicolumn{4}{|l|}{ Urine } \\
\hline Fasting $\mathrm{Ca} /$ creatinine & $0.106(0.064)$ & $0.097(0.078)$ & NS \\
\hline Fasting hydroxyproline/creatinine & $0.065(0.033)$ & $0.059(0.025)$ & NS \\
\hline Fasting GAG $+/$ creatinine & $0.062(0.028)$ & $0.071(0.033)$ & NS \\
\hline Calcium (mg/24 h)* & $101.8(73.6)$ & $85.4(57 \cdot 7)$ & NS \\
\hline Hydroxyproline (mg/24 h)* & $42 \cdot 8(14.6)$ & $38 \cdot 2(19 \cdot 2)$ & NS \\
\hline GAG (mg/24 h) & $48 \cdot 3(28 \cdot 2)$ & $48 \cdot 2(23 \cdot 3)$ & 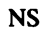 \\
\hline
\end{tabular}

Values are mean (SD).

*SI conversion: total calcium $\mathrm{mg} \% \times 0.250=\mathrm{mmol} / \mathrm{l}$; albumin $\mathrm{g} \% \times 10=\mathrm{g} / \mathrm{l} ; \mathrm{Ca}$ corr. alb. $\mathrm{mg} \% \times 0.250=\mathrm{mmol} /$; phosphorus $\mathrm{mg} \% \times$ $0.323=\mathrm{mmol} / \mathrm{f}$; creatinine $\mathrm{mg} \% \times 88.4=\mu \mathrm{mol} / \mathrm{l} ; 25-\mathrm{OHD}_{3} \mu \mathrm{g} / \mathrm{ml} \times 2.4=\mu \mathrm{mol} / \mathrm{l}$; calcium $\mathrm{mg} / 24 \mathrm{~h} \times 0.0250=\mathrm{mmol} / 24 \mathrm{~h}$; hydroxyproline $\mathrm{mg} / 24 \mathrm{~h} \times 0.00763=\mathrm{mmol} / 24 \mathrm{~h}$.

†Ca corr. alb. = serum calcium corrected for serum albumin level; iPTH = immunoreactive parathyroid hormone; GAG = glycosaminoglycans.

Table 3 Bone mineral content $(B M C)$ at the radius and lumbar spine

\begin{tabular}{|c|c|c|c|}
\hline & $\begin{array}{l}\text { Group I: } R A \\
\text { patients } \\
(n=36)\end{array}$ & $\begin{array}{l}\text { Group II: RA patients } \\
+ \text { corticosteroids } \\
(n=28)\end{array}$ & $\begin{array}{l}\text { Controls } \\
(n=43)\end{array}$ \\
\hline \multicolumn{4}{|l|}{ Peripheral BMC at the distal radius } \\
\hline $3 \mathrm{~cm}\left(\mathrm{~g} / \mathrm{cm}^{2}\right)$ & $0.391(0.084)^{* *}$ & $0.408(0.126)^{*}$ & $0.463(0.091)$ \\
\hline $8 \mathrm{~cm}\left(\mathrm{~g} / \mathrm{cm}^{2}\right)$ & $0.544(0.103)^{* * *}$ & $0.571(0.114)^{*}$ & $0.624(0.096)$ \\
\hline Lumbar BMC L2-L3-L4 (g HA) $\dagger$ & $35.06(7.05)^{*}$ & $30 \cdot 74(8 \cdot 24)^{* * * *}$ & $32.04(5.21)$ \\
\hline
\end{tabular}

Values are mean (SD).

Student's $t$ test: ${ }^{*} \mathrm{p}<0.05$ compared with controls; ${ }^{* *} \mathrm{p}<0.005$ compared with controls; ${ }^{* * *} \mathrm{p}<0.001$ compared with controls; ${ }^{* * * *} \mathrm{p}<0.001$ compared with group $I$.

† $\mathrm{HA}=$ grams hydroxyapatite.

SI conversion: hydroxyapatite $\mathrm{g} \times 0.9954=\mathrm{mmol}$. 


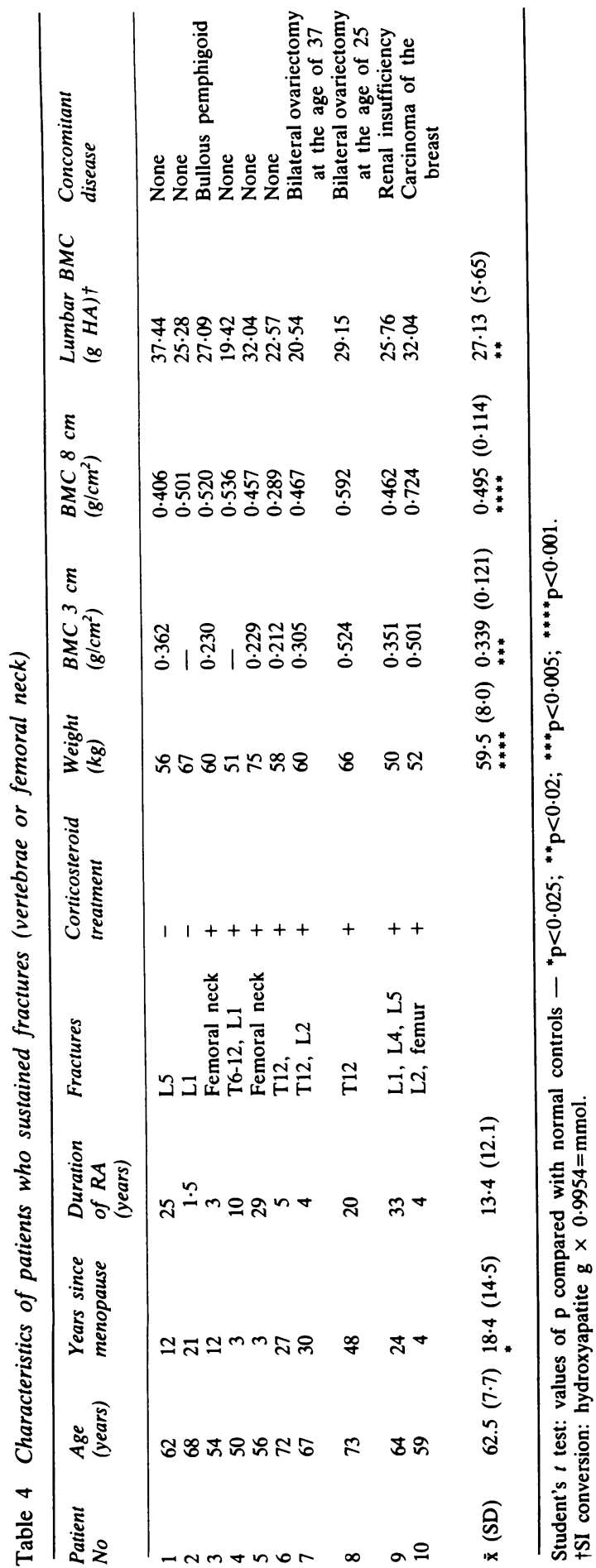

years) and corticosteroid treated patients $(n=14$, mean age $58.8(8.7)$ years and mean disease duration $12.8(4 \cdot 1)$ years).

Values for lumbar BMC were 33.41 (8.97) g HA $(33.26$ (8.93) mmol) v 32.34 (7.51) g HA (32.19 (7.48) mmol) (NS), respectively.

In the control group BMC at the radius $3 \mathrm{~cm}$ and $8 \mathrm{~cm}$ was significantly correlated with $\mathrm{BMC}$ of the axial skeleton $(r=0.548, p<0.001$ and $r=0.452$, $\mathrm{p}<0.005$ respectively). In the RA group this correlation was found only in the corticosteroid treated group, though at a lower level of significance $(\mathrm{p}<0.05)$.

In none of the RA groups was there a correlation between lumbar BMC and biochemical markers of bone turnover. There was also no correlation between duration of corticosteroid treatment and lumbar BMC.

Fractures of vertebrae or femoral neck due to minimal trauma occurred in $9.6 \%$ of the RA group as a whole. The percentage of patients in the corticosteroid treated group who sustained fractures $(16.3 \%)$ was greater than the percentage in the noncorticosteroid treated group (3.6\%).

Table 4 lists the characteristics of the patients with RA who sustained a fracture due to minimal trauma. Three patients had a fracture of the femur and eight had vertebral compression fractures. Four of the 10 patients with fractures had a concomitant disease which might have had an effect on the skeleton. Eight of the patients were on corticosteroid treatment. The difference in fracture rates between the corticosteroid and non-corticosteroid patients was significant $\left(\chi^{2}=6 \cdot 77, p<0 \cdot 01\right)$. This table shows that the patients with RA who sustained fractures were slender in comparison with normal controls. Their values for bone mass, both peripheral and axial, were significantly lower than the values in controls. Their mean period since menopause was longer owing to the fact that some patients underwent ovariectomy at a very young age.

\section{Discussion}

This study conducted in a homogeneous group of postmenopausal patients with RA shows that rheumatoid arthritis does not alter the bone mineral content in the spine, but that corticosteroids even in low dose affect the spine and fracture incidence. The bone mineral content of the peripheral skeleton near the arthritic joints is significantly reduced in RA with no additional effect of steroid treatment. The latter findings agree with previous reports of a lower bone mass at the metacarpals or at the radius in RA, ${ }^{6-8} 1112$ and with our previous longitudinal 
data, ${ }^{4}$ and those of Virtama et al, ${ }^{12}$ which showed that corticosteroid treated patients did not lose more bone from the peripheral skeleton, indicating that inflammation and disuse due to pain and destruction are the main factors involved in peripheral bone loss in RA.

The finding of a significantly increased lumbar BMC in non-corticosteroid treated RA cases is interesting but difficult to explain. It is possible that non-steroidal anti-inflammatory drugs, because of their prostaglandin synthetase inhibiting effect, interfere with bone resorption. It has been shown by Mundy that in vitro prostaglandin $\mathrm{E}_{2}$ stimulates bone resorption. ${ }^{19}$

Differences in lumbar BMC between the two RA groups disappear, however, when a case control study of comparable disease duration in both groups is made. So the difference in lumbar BMC between corticosteroid treated and non-corticosteroid treated patients was due to a difference in disease duration rather than to the corticosteroid treatment.

On the other hand, we observed a significantly higher incidence of fractures in the steroid treated patients. The explanation for this contradictory observation is not clear, but it is possible that corticosteroids alter the quality of the bone rather than the quantity of bone mineral. Another possibility is that the expected low BMC of the spine in steroid treated patients is masked by compression of trabeculae, secondary sclerosis of the end plates, and apophyseal osteoarthritis.

In studies using other measuring techniques, such as neutron activation, significantly lower total body calcium values were found in corticosteroid treated patients with RA which correlated with steroid dosage. ${ }^{13}$ These results, however, cannot be compared with ours since they combined men and women with RA of all ages and since $80 \%$ of the total body calcium represents peripheral cortical bone mass.

McConkey et $a^{16}$ and Hajiroussou and Webley, ${ }^{11}$ using a subjective density grading of $x$ rays of the spine, did not find significant differences between patients with RA receiving low dose corticosteroids or non-corticosteroid treatment. As in our study, McConkey noted that vertebral fracture was seen only in the corticosteroid treated patients. Saville and Kharmosh, on the other hand, found no greater incidence of spinal fractures in those treated with corticosteroids. $^{7}$

The mechanism by which corticosteroids may alter bone quality is not known. Low doses $(5 \mathrm{mg}$ of prednisone) over a 32 week period appear not to affect vitamin $D$ metabolism, ${ }^{22}$ but high dose prednisone therapy may lead to secondary altera- tions in 25-hydroxyvitamin D metabolism ${ }^{23}$ and to a marked decrease in intestinal calcium absorption. ${ }^{24} \frac{\mathrm{O}}{\mathrm{c}}$

In this study 25-hydroxyvitamin D levels were normal, as were serum levels of immunoreactive $\stackrel{\text { S }}{+}$ PTH. The latter observation is in contrast with the finding of Fucik et al, who found an increased PTH level in corticosteroid treated patients. ${ }^{25}$

Despite the evidence presented in this paper on $\frac{\widehat{Q}}{\varnothing}$ the lack of effect of corticosteroids on lumbar bone mineral content in RA compared with the effect on normal controls we think that the increased inci- dence of pathological fractures in patients receiving $\overrightarrow{\vec{\omega}}$ corticosteroids for RA and other conditions ${ }^{26}$ estab- $\rho$ lishes the deleterious effect of this drug on bone quality in some patients. Since the incidence of steroid induced osteoporosis is less than $50 \%$ there is a need to identify the patients at risk and apply $\vec{\circ}$ preventive measures. This study points to the of patient at risk being the postmenopausal women, especially the slender one. ${ }^{27}$

Frumar $e t$ al showed that obesity protected against excess calcium loss and bone resorption, ${ }^{28}$ indicating a relation between body weight, circulating oes- $\frac{0}{0}$ trogens, and urinary calcium loss.

In the postmenopausal women androstenedione $\vec{\bullet}$ from the adrenal gland becomes converted oestradiol in the subcutaneous fat. In the presenee. of exogenous corticosteroids the pituitarits hypothalamic axis is suppressed, resulting in diminished output of androstenedione from the adrenalo gland and thus lower serum oestrogen levels.

\section{References}

1 Rosenspire K C, Kennedy A C, Steinbach J, Blau M, Green F A. 3 Investigation of the metabolic activity of bone in rheumatoid arthritis. J Rheumatol 1980; 7: 469-73.

2 Rajapakse C, Thompson R, Grennan D M, et al. Increased:bone metabolism in rheumatoid arthritis as measured by the whole body retention of ${ }^{99} \mathrm{Tc}^{\mathrm{m}}$ methylene diphosphonate. Ann? Rheum Dis 1983; 42: 138-41.

3 Helfgott S, Rosenthall L, Esdaile J, Tannenbaum H. General ized skeletal response to ${ }^{99 \mathrm{~m}}$ technetium methylene diphosphon-응 ate in rheumatoid arthritis. J Rheumatol 1982; 9: 939-41.

4 Dequeker J, Wielandts L, Koentges D, Nijs J. The assessment of bone loss in rheumatoid arthritis. In: Feltkamp T E W, Van der Korst J K, eds. Proceedings VISRA Symposium. Alphen $>$ aan den Rijn/Brussel: Stafleu's Scientific Publishing Company, 을. 1979: 54-63.

5 Kennedy A C, Lindsay R. Bone involvement in rheumatoid arthritis. Clin Rheum Dis 1977; 3: 403-20.

6 Bjelle A O, Nilsson B E. Osteoporosis in rheumatoid arthritis. $N$ Calcif Tissue Res 1970; 5: 327-32.

7 Saville P D, Kharmosh O. Osteoporosis of rheumatoid arthritis: influence of age, sex, and corticosteroids. Arthritis Rheum $1967 ; 0$ 10: $423-30$

8 Skibsted Als O, Christiansen C, Hellesen C. Prevalence of decreased bone mass in rheumatoid arthritis. Relation tow anti-inflammatory treatment. Clin Rheumatol 1984; 3: 201-8. :

9 Kennedy A C, Smith D A, Buchanan W W, Anderson J B. Jasani H K. Bone loss in patients with rheumatoid arthritis Scand J Rheumatol 1975; 7: 73-9. 
10 Kennedy A C, Smith D A, Anton H C, Buchanan W W. Generalised and localised bone loss in patients with rheumatoid arthritis. Scand J Rheumatol 1975; 4: 209-15.

11 Hajiroussou V J, Webley M. Prolonged low-dose corticosteroid therapy and osteoporosis in rheumatoid arthritis. Ann Rheum Dis 1984; 43: 24-7.

12 Virtama P, Helelä T, Kalliomäki J L. Osteoporosis in rheumatoid arthritis. Acta Rheumatol Scand 1968; 14: 276-84.

13 Reid D M, Kennedey N S J, Smith M A, Tothill P, Nuki G. Total body calcium in rheumatoid arthritis: effects of disease activity and corticosteroid therapy. Br Med J 1982; 285: 330-2.

14 Bjelle A O, Nilsson B E. The relationship between radiological changes and osteoporosis of the hand in rheumatoid arthritis. Arthritis Rheum 1971; 14: 646-9.

15 Duncan H. Osteoporosis in rheumatoid arthritis and corticosteroid induced osteoporosis. Orthop Clin North Am 1972; 3: 571-83.

16 McConkey B, Fraser G M, Bligh A S. Osteoporosis and purpura in rheumatoid disease: prevalence and relation to treatment with corticosteroids. $Q J$ Med 1962; 31: 419-27.

17 Cameron J R, Sorenson J. Measurement of bone mineral in vivo: an improved method. Science 1963; 142: 230-2.

18 Krolner B, Pors Nielsen S. Measurement of bone mineral content (BMC) of the lumbar spine. I. Theory and application of a new two dimensional dual photon attenuation method. Scand J Clin Lab Invest 1980; 40: 653-63.

19 Mundy G R. Monocyte macrophage system and bone resorption. Lab Invest 1983; 49: 119-21.

20 Ropes H W, Benett C A, Cobbs S, Jacox R, Jenar R A.
Proposed diagnostic criteria for rheumatoid arthritis. Ann Rheum Dis 1957; 16: 113.

21 Verstraeten A, Dequeker J. Mineral metabolism in postmenopausal women with active rheumatoid arthritis. $J$ Rheumatol (in press).

22 Harris E D Jr, Emkey R D, Nichols J E, Newberg A. Low dose prednisone therapy in rheumatoid arthritis: a double blind study. J Rheumatol 1983; 10: 713-21.

23 Hahn T J, Halstead L R, Teitelbaum S L, Hahn B H. Altered mineral metabolism in glucocorticoid induced osteopenia: effect of 25-hydroxyvitamin D administration. J Clin Invest 1979; 64: 656-65.

24 Hahn T J, Halstead L R, Barran D T. Effects of short term glucocorticoid administration on intestinal calcium absorption and circulating vitamin D metabolite concentrations in man. $J$ Clin Endocrinol Metab 1981; 52: 111-5.

25 Fucik R F, Kukresja S C, Hargis C K, Bowser E N, Henderson W J, Williams G A. Effect of glucocorticoids on function of the parathyroid glands in man. J Clin Endocrinol Metab 1975; 40: 152-5.

26 Baylink D J. Corticosteroid induced osteoporosis. N Engl J Med 1983; 309: 306-10.

27 Dequeker J, Goris P, Uytterhoeven R. Osteoporosis and osteoarthritis (osteoarthrosis): anthropometric distinctions. JAMA 1983; 11: 1448-51.

28 Frumar A M, Meldrum D R, Geola F, et al. Relationship of fasting urinary calcium to circulating estrogen and body weight in postmenopausal women. J Clin Endocrinol Metab 1980; 50: $70-5$. 